\title{
Impactos da indisciplina no currículo: implicações para os contextos de ensino e aprendizagem
}

\author{
Flávio Fernando de Souza*
}

\begin{abstract}
Resumo
Neste estudo teórico, objetiva-se compreender de que formas a indisciplina impacta as decisões dos professores sobre o currículo e as implicações disso para os contextos de ensino e aprendizagem. Parte-se da compreensão de currículo como prática construída histórica e socialmente, um campo marcado pelo conflito, especialmente modelado pelos professores a partir dos confrontos com as indisciplinas dos alunos. Têm-se como referencial teórico os estudos de Sacristán, Arroyo, Garcia, Moreira, Candau e Silva, com base em que se analisa a relação entre indisciplina e currículo. Como contraponto, analisam-se os achados de uma investigação (ENNIS, 1996) sobre os efeitos da indisciplina na prática de professores, a partir do que se conclui a convergência entre o contexto da sala de aula e suas implicações na prática docente e, consequentemente, na aprendizagem dos alunos, em decorrência de como os professores interpretam os significados da indisciplina e a ela reagem na (re)elaboração de sua prática.

Palavras-chave: Educação; Currículo; Indisciplina; Professores; Ensino e Aprendizagem.
\end{abstract}

\section{Indiscipline's impacts in the curriculum: implications for teaching and learning contexts}

\begin{abstract}
In this theoretical study aims to understand in what ways indiscipline impact on teachers' decisions on curriculum and its implications for teaching and learning contexts. It starts with the understanding of curriculum as historically and socially constructed practice, a field marked by conflict, especially shaped by teachers starting from confrontations with the pupils' indiscipline. It has as theoretical reference the Sacristán, Arroyo, Garcia, Moreira, Candau and Silva studies, based on which we analyse the relationship between indiscipline and curriculum. As a counterpoint, the findings of a research (ENNIS, 1996) are analysed on the effects of indiscipline in the teachers's practice, from which it concludes the convergence between the classroom context and its implication on teaching practice and, consequently, on student learning as a result of how teachers interpret the indiscipline's meanings and react to them in the (re) development of their practice.

Keywords: Education; Curriculum; Indiscipline; Teachers; Teaching and Learning.
\end{abstract}

\section{Introdução}

A literatura educacional sobre o currículo é um campo amplo de estudos que comporta uma pluralidade de significados e teorias explicativas. Dada essa pluralidade, pode referir-se ao professor, ao planejamento, ao projeto político-pedagógico da escola, aos conteúdos, aos alunos e às atividades por eles desenvolvidas, à prática pedagógica de ensinagem e de aprendizagem, conforme as ênfases determinadas pela racionalidade que o define recaiam sobre o conteúdo, a experiência, as atividades ou a própria organização do currículo. Contudo, conforme Pedra (2000, p. 31), "os variados conceitos atribuídos ao termo currículo não descrevem realidades diferentes, apenas informam sobre a interpretação que determinado autor ou escola teórica lhe deu", o que caracteriza, por conseguinte, segundo esse mesmo autor, que o conceito de currículo depende da perspectiva que se adote e não propriamente da polissemia do termo.
O conceito de currículo, portanto, pode assumir diferentes significados conforme o enfoque paradigmático que se adote, e também conforme a sua utilização para indicar distintos processos envolvidos na organização curricular escolar que, segundo Sacristán (2000, p. 104-106), expressam-se em seis níveis ou fases no processo de desenvolvimento do currículo e que englobam: as determinações dos setores da administração educacional que se expressam através do currículo prescrito (ou oficial); os materiais didáticos que se configuram em 'tradutores' do currículo prescrito, ou seja, são os meios mediante os quais o currículo oficial é apresentado aos professores; os planejamentos dos professores mediante os quais se traduzem as expectativas oficiais e se concretiza o currículo e que, portanto, constituem o currículo moldado pelos professores, de forma individual ou coletiva na escola; as tarefas e atividades escolares que efetivamente constituem a prática, a ação pedagógica, o currículo em ação; as aprendizagens

* Endereço eletrônico: prof.flaviofsouza@gmail.com 
dos alunos que compõem o currículo realizado e se traduzem em "[...] efeitos complexos dos mais diversos tipos: cognitivo, afetivo, social, moral etc." (Ibid., p. 106), e que afetam tanto os alunos quanto os professores; e, ainda, as expectativas e/ou objetivos de quem prescreveu ou elaborou o currículo em relação aos critérios estabelecidos sobre os resultados esperados na aprendizagem dos alunos, bem como sobre a ensinagem dos professores, ou seja, o currículo avaliado, que se torna assim instrumento de controle sobre alunos e professores, o que para o autor é inerente "[...] à função social estratificadora da educação e acaba por configurar toda uma mentalidade que se projeta inclusive nos níveis de escolaridade obrigatória e em práticas educativas que não têm uma função seletiva nem hierarquizadora" (Id.).

Desse modo, o currículo, conforme as diversas ênfases que se estabelecem em seu processo de constituição, pode ser visto como um objeto que sofre diversas intervenções, "[...] que cria em torno de si campos de ação diversos, nos quais múltiplos agentes e forças se expressam em sua configuração, incidindo sobre aspectos distintos" (Ibid., p. 101). Nesse sentido, pode-se entender o currículo como prática, “[...] uma prática na qual se estabelece um diálogo, por assim dizer, entre agentes sociais, elementos técnicos, alunos que reagem frente a ele [e] professores que o modelam" (Ibid., p. 16). Portanto, o currículo realiza-se por meio de uma prática pedagógica em que confluem múltiplos agentes e forças enquanto "[...] resultado de uma série de influências convergentes e sucessivas, coerentes ou contraditórias, adquirindo, dessa forma, a característica de ser um objeto preparado num processo complexo, que se transforma e constrói no mesmo" (Ibid., p. 102).

Neste estudo teórico, tendo-se em vista compreender de que formas a indisciplina impacta as decisões dos professores sobre o currículo e as implicações disso para os contextos de ensinagem e de aprendizagem, parte-se desta compreensão de currículo enquanto objeto historicamente construído, um campo naturalmente marcado por conflitos de interesses e perspectivas que se abrem para além do contexto das determinações oficiais, para perspectivas de mudança, advindas quer das escolhas de seus agentes (professores, alunos, pais, intelectuais, legisladores etc.), quer de impactos das forças de resistência e contestação que representam as indisciplinas dos alunos em sala de aula, bem como da modelagem por parte dos professores em decorrência desses contextos.

Por conseguinte, neste texto inicialmente se explora o conceito de currículo como prática, construída histórica e socialmente, atravessada por relações de poder, com base em um conjunto de teóricos nacionais e estrangeiros: Sacristán (2000), Arroyo (2001, 2007 e 2011), Garcia (2010a), Moreira (2007), Moreira e Candau (2007), Moreira e Silva (2011) e Silva (1995, 2008 e 2011). Depois, com base nesse referencial teórico, analisa-se a indisciplina como força transformadora do currículo praticado. Por último, com base nas conclusões e provocações suscitadas pela pesquisa de Ennis (1996) com professores de dez escolas de Ensino Médio estadunidense, em contexto urbano, em salas multiculturais e disruptivas, aborda-se a questão de como, sob diferentes formas, os confrontos produzidos entre os alunos indisciplinados e os professores podem interferir no gerenciamento da sala de aula e nas decisões sobre os conteúdos, atividades e métodos planejados pelos professores.

\section{O currículo como prática}

O currículo, segundo Sacristán (2000, p. 14), não é um conceito, mas uma prática, uma construção cultural, em que confluem múltiplos processos e agentes mutuamente imbricados, ou seja, uma prática que informa e conforma seus sujeitos, mas que também é configurada por estes. $\mathrm{E}$, sendo uma prática, engloba uma pluralidade de significações construídas historicamente como respostas a teorias e ideologias de determinadas sociedades, configurando-se como um conjunto de experiências, atividades, planejamentos, conteúdos, políticas etc., em razão do ordenamento das funções e finalidades da escola e seus modos de fazer, de tais maneiras dirigidas tanto as professores, enquanto executores, quanto aos alunos, tendo em vista os objetivos de aprendizagem que devem atingir e os modos para tal. Pode-se afirmar, com base nisto, que o professor e igualmente o aluno são sujeitos, "[...] agentes ativos no processo" (Ibid., p. 165), ao mesmo tempo moldados pelas intenções, finalidades e práticas curriculares, mas que também no processo de tradução destas pelos professores na prática, e contestadas ou sob a resistência das indisciplinas dos alunos, sofrem um processo de reconfiguração.

Em seus conteúdos e formas, o currículo resulta de escolhas. Escolhas informadas ideologicamente a partir de "[...] uma opção historicamente configurada, que se sedimentou 
dentro de uma determinada trama cultural, política, social e escolar; está carregado, portanto, de valores e pressupostos que é preciso decifrar" (SACRISTÁN, 2000, p. 17). O que implica a necessidade de desvendar que tipos de ações intervêm em sua configuração, quais as condições concretas de sua realização, as determinações culturais, sócio-políticas e econômicas que informam e conformam seus processos. Para que isso seja possível, não se pode separar o seu processo de construção das condições reais de seu desenvolvimento, ou seja, em sua abordagem há que se levar em conta que o currículo está

\section{[...] num sistema educativo, o que requer prestar atenção às práticas políticas $e$ administrativas que se expressam em seu desenvolvimento, às condições estruturais, organizativas, materiais de dotação do professorado, à bagagem de ideias $e$ significados que lhe dão forma e que o modelam em sucessivos passos de transformação (Ibid., p. 21).}

Por conseguinte, entende-se que o currículo é conformado "[...] dentro de um sistema escolar concreto, dirige-se a determinados professores e alunos, serve-se de determinados meios, cristaliza, enfim, num contexto, que é o que acaba por lhe dar o significado real" (Id.), diante do que só uma investigação informada pelo pensamento crítico pode desvelar as realidades que o condicionam, e colocar-se em evidência um complexo e intricado processo de constituição do currículo, que se expressa em uma série de determinações das políticas de educação, da sequenciação dos conteúdos nos materiais didáticos à disposição dos professores, dos saberes legitimados pelos professores como necessários e socialmente válidos, bem como pelos intercâmbios entre os professores e alunos na sala de aula. O currículo constitui, desse modo, "[...] o cruzamento de práticas diferentes e se converte em configurador, por sua vez, de tudo o que podemos denominar como prática pedagógica nas aulas e nas escolas" (Ibid., p. 26), em consequência do que pode-se afirmar também que a própria relação pedagógica professor-aluno é configurada pelo currículo, expressando-se nas expectativas de ambos, um em relação ao outro e também em relação a eles mesmos no sentido dos resultados e expectativas de aprendizagem e de ensino.

Assim sendo, preocupações com o "[...] o fracasso escolar, a desmotivação dos alunos, o tipo de relações entre estes e os professores, a disciplina em aula, a igualdade de oportunidades" (Id.), têm, segundo Sacristán, relação direta com o que se oferece aos alunos e o modo como se oferece e, portanto, com o currículo. Ou seja, "quando os interesses dos alunos não encontram algum reflexo na cultura escolar, se mostram refratários a esta sob múltiplas reações possíveis: recusa, confronto, desmotivação, fuga" (Ibid., p. 30), resistência e indisciplinas.

Em decorrência disso a sala de aula, o planejamento, os conteúdos, o currículo praticado, configuram-se, afirma Arroyo (2011, p. 10), enquanto "[...] espaços onde se vivenciam realizações, mal-estares e até crises da docência; [...] tanto mestres quanto alunos experimentam frustrações, desânimos, incertezas, cansaço... mas, também vivenciam realizações, compromissos ético-políticos que vão configurando outros profissionais e outros educandos."

Múltiplas, portanto, são as demandas que contestam e disputam esse território, advindas quer das políticas de currículo, quer das condições de sua efetivação nas escolas e da ação dos sujeitos da prática pedagógica, fazendo do currículo, de alguma forma, como que um reflexo dos conflitos entre os interesses de uma dada sociedade e "[...] os valores dominantes que regem os processos educativos" (SACRISTÁN, 2000, p. 17), diante do que, ainda que se busque de maneiras diversas e a serviço de interesses hegemônicos, assegurar alguma forma de reprodução direta desses interesses na organização do cotidiano escolar, verificam-se, contudo, conforme afirma Moreira (2007, p. 109), "[...] sensíveis diferenças entre os textos das propostas e as interpretações que delas se fazem nas escolas e salas de aulas - efetuam-se verdadeiras leituras negociadas, por vezes criativas e inovadoras, por vezes confusas e contraditórias" (grifos do autor).

Essas constatações sugerem que, em se tratando da questão curricular, e para a continuidade desta análise, há que se aclarar e diferenciar pelo menos três concepções fundamentais da compreensão sobre currículo, entendido como currículo oficial, currículo oculto e currículo praticado. Por currículo oficial ou formal, conforme Garcia (2010a, p. 48), entende-se "[...] o conjunto de elementos ou expectativas de aprendizagem que formalmente compreendem o currículo na escola". Por currículo praticado ou currículo em uso, segundo a acepção proposta por Moreira (1998, p. 21), entende-se o que Garcia (2010a, p. 49) 
denomina "[...] um conjunto de práticas de ensinoaprendizagem que são efetivamente exercidas pelos professores na escola". E, ainda, o currículo oculto, que envolve, como afirmam Moreira e Candau (2007, p. 18),

[...] atitudes e valores transmitidos, subliminarmente, pelas relações sociais e pelas rotinas do cotidiano escolar, [que se traduzem através de] rituais e práticas, relações hierárquicas, regras $e$ procedimentos, modos de organizar o espaço e o tempo na escola, modos de distribuir os alunos por agrupamentos $e$ turmas, mensagens implícitas nas falas dos(as) professores(as) e nos livros didáticos.

Assim, o currículo que se expressa sob a forma de representação oficial, praticado ou oculto, constitui o trabalho pedagógico de ensinagem e de aprendizagem, estabelecendo-se, segundo Arroyo (2007, p. 18), “[...] o núcleo fundante e estruturante do cotidiano das escolas, dos tempos e espaços, das relações entre educadores e educandos, da diversificação que se estabelece entre os professores". Para esse autor, é necessário que o professor compreenda esaa relação entre o currículo e a organização de seu trabalho na escola, de forma a lhe facilitar o entendimento sobre as implicações disto nas suas ações e escolhas e apreender que lógicas, concepções e valores estão sendo legitimados por elas (Ibid., p. 19).

Enquanto núcleo estruturante do trabalho e do cotidiano escolar, portanto, o currículo se constitui a/na própria prática pedagógica, e se estabelece, conforme Silva (1995, p. 184), enquanto o "[...] conjunto de todas as experiências de conhecimento proporcionadas aos/às estudantes", como centro em torno do qual gravitam, se estruturam e se organizam todos os processos desta prática, sempre resultando de uma seleção de conhecimentos, saberes e valores (SILVA, 2011, p. 15), ao mesmo tempo em que "[...] corporifica relações sociais" (SILVA, 1995, p. 201). Tem-se, por conseguinte, conforme Moreira e Silva (2011, p. 13-14), o currículo como "[...] um artefato cultural e social [...], implicado em relações de poder, [que] transmite visões sociais particulares e interessadas".

No currículo, desse modo, em todas as suas formas, não há neutralidade, há sim intencionalidades e escolhas, das quais resultam ênfases e omissões, ocultamentos e silenciamentos, constituindo-se um território de disputa (ARROYO, 2011), um território contestado (SILVA, 1995), no qual "[...] se travam ferozes competições em torno de significados, [...] referindo-se, portanto, à criação, recriação, contestação e transgressão" (MOREIRA e CANDAU, 2007, p. 28).

Tal compreensão possibilita pensar o currículo como invenção humana, uma construção histórica, passível de desnaturalização e desconstrução, de desestabilização e, por conseguinte, de ser transformado, o que permite tornar-se, segundo afirmam Moreira e Candau (2007, p. 30), fonte de "[...] estímulo para resistência, para crítica e para a reformulação e a promoção de novas situações pedagógicas e novas relações sociais".

Com base nesse entendimento, no próximo tópico, explora-se uma noção de indisciplina enquanto uma destas forças de resistência, que exerce uma função produtiva, conforme anunciada por Garcia (2010b, p. 401), e que se estabelece através da desestabilização da prática pedagógica e da relação professor-aluno, de modo a impactar esse contexto, essa relação e, portanto, o currículo.

\section{A indisciplina como força transformadora do currículo}

Uma vez que se entenda o currículo enquanto um campo de práticas, um objeto histórica e socialmente construído, marcado pelo conflito entre determinações e resistências, entre expectativas e modelações contestadoras, ou seja, produzido na tensão entre a fixação e a abertura às mudanças, é possível apreender sua concretização, para além de concepções com enfoque reprodutivista, como uma atividade produtiva, como defende Silva (2008, p. 194-195), segundo o qual "[...] nós fazemos o currículo e o currículo nos faz; [...] como qualquer outro artefato cultural, como qualquer outra prática cultural, o currículo nos constrói como sujeitos particulares, específicos". Está, portanto, implicado no currículo um processo de constituição de subjetividades e de identidades sociais, ou seja, um processo de "[...] constituição do indivíduo como um sujeito de um determinado tipo e de seu múltiplo posicionamento no interior das diversas divisões sociais" (Ibid., p. 195), do que decorre a necessidade de se estar atento aos processos de produção das identidades daqueles, conforme o foco deste estudo, entendidos como sujeitos da prática pedagógica - professores e 
alunos.

Conforme Arroyo (2011), percebe-se instalado na escola um movimento de repensar os currículos, percepção essa que o leva a advogar uma reconfiguração da identidade docente, associada a uma maior sensibilidade dos professores para as questões curriculares nas escolas, em decorrência de uma percepção mais clara na atualidade de que a organização curricular afeta a organização de seu trabalho e de seu trabalho com os alunos. Os professores estariam assim, conforme sugere, reconstituindo sua identidade profissional docente enquanto "[...] sujeito social, político, cultural e também pedagógico" (ARROYO, 2000, p. 137). Ao manifestarem suas resistências, os professores reinventam suas formas de trabalho, "[...] reagem à condição de aulistas e avançam na autoria de sua prática" (ARROYO, 2007, p. 20).

Nesse processo, se de um lado os professores têm se constituem autores de suas práticas, por outro, há os alunos, que também reclamam por reconhecimento de suas identidades culturais, sociais e pedagógicas, como " [...] sujeitos ativos, afirmativos, de direitos e não destinatários agradecidos" (ARROYO, 2011, p. 256). São, portanto, "[...] presenças incômodas e desestruturantes" (Ibid., p. 237), que se expressam de maneiras distintas por meio, sobretudo, de suas atitudes indisciplinares, que tencionam essa relação exigindo, por sua vez, que se construam novas visões, novas práticas e novas relações pedagógicas, contestando e resistindo aos currículos, remodelando tempos e espaços escolares e seus ordenamentos, confrontando-se com os conteúdos da docência e as lógicas em que estes são estruturados e com base nas quais se determinam e ordenam os conhecimentos a serem aprendidos e as formas e tempos para que isso ocorra.

As implicações da indisciplina para $o$ currículo, desse modo, ocorrem em via de mão dupla, em um território compartilhado, mas também contestado e disputado entre professores e alunos. De um lado, o currículo é produzido com base em uma racionalidade específica, que determina, por exemplo, um inventário de conteúdos oficiais a serem ensinados e expectativas a serem atingidas, e, concomitantemente, prescinde também de um professor que os transmita e de um tipo ideal de aluno (SACRISTÁN, 2005), capazes de realizar as tarefas de ensino e aprendizagem. Assim, o currículo produz identidades escolares com resultado de seu ordenamento, de sua lógica interna, constituindo-se como que um molde a conformar os sujeitos da prática pedagógica segundo aquela visão estruturante pela qual é informado. De outro lado, contudo, sofre de ação reversa, pois os alunos também agem sobre o currículo, assim como os professores. Como? Quando, por exemplo, o professor reflete sobre como ensinar, o que ensinar e qual a melhor forma de fazê-lo, pensando em situações específicas de encontro com as indisciplinas dos alunos, de um aluno em particular ou de um grupo, ou turma, a partir das quais produz modificações no currículo, tendo em vista minimizar estas tensões. Ou seja, o currículo praticado em sala de aula não fica imune aos filtros colocados pelos professores, com base em inúmeras questões de ordens diversas, teóricas e práticas, formativas desse modo de seu agir pedagógico e, menos ainda, não imune às indisciplinas dos alunos, conforme a tese sustentada por Garcia (2010a, p. 48) de que "[...] a indisciplina dos alunos, sob diferentes formas, é capaz de transformar as decisões sobre o currículo".

Para esse autor, o currículo praticado é mais suscetível à influência das decisões dos professores (Ibid., p. 50), uma vez que, situado no território da sala de aula e sofrendo inúmeras interferências advindas sejam das escolhas dos próprios professores em relação aos conteúdos ou aos métodos, oriundas também de referências a experiências anteriores de encontros com as situações de indisciplina em sala de aula, seja pela influência da indisciplina dos alunos manifestando resistência, contestação, ruptura, descontentamento, ou mesmo esvaziamento, em relação principalmente ao distanciamento entre aquilo que se propõe como expectativa ou culturalmente necessário e o cotidiano da vida e das experiências dos alunos.

A indisciplina estaria se configurando, nesse contexto, "[...] como uma contestação baseada no discernimento da distância entre os valores sinalizados aos alunos, e as finalidades e práticas educacionais desenhadas para eles" (GARCIA, 2010b, p. 400). Se, de um lado, a indisciplina estaria comunicando esse distanciamento entre as expectativas e interesses dos alunos, omitidos e silenciados na escola, por outro - e conforme as diversas leituras desse fenômeno no contexto escolar -, poderia indicar também "[...] um desejo de estabelecer referências novas na escola, que poderiam inspirar, por exemplo, diferentes formas de equacionar as relações de poder entre professores e alunos, bem como novas perspectivas para o currículo" (Id.). Dessa forma, as indisciplinas dos alunos implicam múltiplas formas de impactos na 
prática pedagógica, no currículo pretendido e planejado pelo professor, especialmente levando-se em consideração os modos pelos quais os professores interpretam seus significados e com base nos quais (re)elaboram suas estratégias didáticas.

Compreender quais são essas implicações dos impactos da indisciplina sobre o currículo, no que diz respeito aos efeitos que produzem na prática dos professores, constitui-se objetivo da análise a seguir. Para isso, toma-se como base a investigação desenvolvida por Ennis (1996) em dez escolas urbanas de um distrito no leste dos Estados Unidos, um contexto marcado pelo multiculturalismo, onde, dos 110.000 estudantes do distrito, 69\% são afroamericanos, oriundos de famílias de classes populares, e $80 \%$ dos professores são de origem euro-americana. Alerta-se, no entanto, que essa investigação teve como foco a percepção dos professores entrevistados sobre os confrontos com alunos indisciplinados em suas salas de aula e suas implicações nas decisões sobre o gerenciamento da sala e do conteúdo, e não inclui, portanto, as percepções dos alunos sobre o fenômeno em estudo (ENNIS, 1996, p. 3).

\section{Implicações da indisciplina para a prática docente}

A pesquisa desenvolvida por Ennis (1996) foi realizada após cinco anos de consultoria e formação de professores no distrito, com reflexões sobre temas como o desenvolvimento curricular e a motivação dos alunos. Procedeu-se também à observação das aulas durante um período de seis semanas nas turmas, segundo classificação atribuída pelos professores entrevistados, consideradas a partir do clima/contexto da sala de aula em três graus: melhor, médio e mais difícil. Foram entrevistados 10 professores das áreas de inglês, matemática, ciências, música e educação física, com 21 a 38 anos de experiência docente, sendo sete deles euro-americanos e três afro-americanos, com o objetivo de analisar os impactos do confronto com os alunos indisciplinados no currículo pretendido pelos professores (Ibid., p. 2).

Segundo a pesquisadora, com base nos estudos de Erickson e Shultz (1992 apud ENNIS, 1996, p. 1) ${ }^{1}$, o confronto entre professores e alunos "[...] parecem surgir quando os alunos percebem que não estão sendo tratados de forma justa, ou porque não concebem o conteúdo como útil, ou simplesmente porque eles estão entediados e reconhecem que os confrontos adicionam emoção à monotonia de um dia de escola". O confronto, conforme sugerem esses autores, cria um contexto desfavorável à aprendizagem, um mal estar nos professores que pode resultar em um posicionamento defensivo ou de recuo da parte dos professores, e que tem como consequência a limitação das oportunidades de aprendizagem que proporcionam aos alunos - diante do que se pressupõe, portanto, uma relação convergente entre o clima que se estabelece no contexto da sala de aula e seus efeitos na prática docente e, consequentemente, nas expectativas e nos contextos de aprendizagem proporcionados aos alunos.

Em contextos como os analisados nesta pesquisa, em que o confronto se mostra agudizado entre, de um lado, os professores em suas tentativas por manter a gestão e o controle sobre a aula, e de outro, os alunos tentando afirmar suas próprias formas de controle tendo em vista criar um ambiente escolar diferente daquele que lhes é proporcionado, os dados indicam que, em decorrência disso, os professores alteram o currículo pretendido, quando não desistem de suas aulas e do cuidado com a aprendizagem de seus alunos, evitando os conteúdos polêmicos e apoiando-se no retorno a práticas tradicionais de ensino.

Com relação às causas desse recuo dos professores quanto ao que pretendiam ensinar aos alunos e também no modo como pretendiam fazê-lo, apontam-se, na perspectiva dos professores entrevistados, três motivos principais: primeiro, porque acreditam que os alunos são desinteressados; segundo, porque entendem que os alunos se recusam a aprender ou a participar das atividades propostas; e, terceiro, porque a abordagem de determinados conteúdos gera confrontos diante dos quais não se sentem preparados para fazer a mediação em sala de aula (ENNIS, 1996, p. 3). Ressaltam que, além disso, sentem-se abandonados pelos setores e pessoal administrativo da escola e também não recebem o apoio dos pais quando em suas tentativas de resolução dos conflitos.

As indisciplinas dos alunos, conforme a percepção dos professores entrevistados por Ennis, que se expressam através de sua desmotivação, desinteresse ou recusa pelos estudos, parece encontrar reforço em uma crença comum ao universo docente, relatada por todos durante as entrevistas, segundo a qual os professores justificam já ter tentado de tudo para motivar os seus alunos, mas que seus esforços resultaram improdutivos, uma vez que, em seu entendimento, mesmo assim 
os alunos se recusam a aprender. Para a pesquisadora, porém, a atribuição de culpa ao aluno, de culpa ao professor, ao sistema ou aos pais constitui uma percepção superficial e de fuga ao problema e, por isso mesmo, é improdutiva para a compreensão ou resolução dos conflitos. Ela afirma, nesse sentido, que não se trata de atribuir culpa a este ou àquele; é preciso desvelar as razões subjacentes aos confrontos e ao desinteresse, resultantes, entre outros motivos, "[...] de décadas de subserviência cultural e econômica" (ENNIS, 1996, p. 5), bem como da fragmentação curricular, da rigidez das práticas disciplinares, e também da situação econômica vivida por esses estudantes, de suas múltiplas e radicais experiências de vida nos contextos sociais a que estão submetidos e, que em razão destes, percebem o desligamento do currículo com suas próprias vidas.

Além do desinteresse, há indisciplinas que se expressam pela recusa dos alunos em participar de certas atividades (Ibid., p. 6-7), diante do que a reação dos professores se traduz em desviar-se da proposição dessas atividades, entendidas como provocadoras de confrontos, porque estariam expondo a baixa autoestima dos estudantes que não se sentem capazes de um bom desempenho. Como estratégias diante disso, os professores, tendo em vista evitar os comportamentos desafiadores e disruptivos dos alunos, tendem a evitar atividades baseadas, por exemplo, em solicitações de respostas orais diante de toda a turma em sala de aula, apresentações de trabalhos e até mesmo a escrita na lousa, consequentemente diminuindo suas exigências quanto ao cumprimento de determinadas tarefas e atividades.

Por outro lado, os dados também indicam que o recuo dos professores diante dos confrontos com as indisciplinas dos alunos em relação aos conteúdos que pretendiam pode resultar, além disso, de sua dificuldade em mediar esses confrontos em sala, ou da sua falta de habilidade em lidar com a distribuição do poder em sala de aula e permitir aos alunos algum tipo de controle sobre o currículo, ou seja, de exercer um poder partilhado democraticamente com eles. Tal situação, conforme propõe a pesquisadora, manifesta uma crença bastante presente entre os professores de que seu papel e, portanto, sua identidade docente se traduziria na função de transmitir, de comunicar aos alunos os conteúdos prescritos e de que qualquer interferência, portanto, na esfera de controle que viesse abalar a posição de quem é o responsável pelas decisões resultaria em caos (Ibid., p. 9). Desse modo, ainda que entendessem a necessidade de adaptar conteúdos e atividades aos contextos de aprendizagem de seus alunos e suas salas de aula, eles percebiam como potencialmente explosivo permitir que os estudantes influenciassem o currículo segundo suas próprias expectativas, diante do que se sentiam despreparados e abandonados pela administração e pelas famílias, para mediar e gerenciar tais situações e, que, portanto, deveriam ser evitadas.

\section{Considerações finais}

O currículo, portanto, conforme o foco deste estudo, além de constituir-se como núcleo fundante e estruturante do trabalho pedagógico; como conjunto das experiências de conhecimento proporcionadas pela escola aos estudantes; como artefato cultural; como invenção histórico-cultural; como lugar do encontro e de produção de identidades dos sujeitos da prática educativa professores e alunos, marcado por tensões, ênfases e omissões, escolhas, relações de poder e de resistência; constitui-se, igualmente, como prática social, uma prática de diálogo entre sujeitos que, de um lado, o modelam e, de outro, a ele reagem, uma interação em que ambos agem constitutivamente sobre o currículo e são por ele constituídos (SACRISTÁN, 2000, p. 16). Assim, enquanto campo de atividades em que confluem múltiplos agentes e forças (Ibid., p. 101-106), pode-se perceber um movimento relacional, por vezes conflitivo, tenso, desestruturante que se estabelece entre as referências oficiais de ordenação curricular, que se poderiam chamar de expectativas ou de conteúdos considerados culturalmente necessários, nas priorizações estabelecidas nos projetos pedagógicos das escolas e nos materiais didáticos fornecidos aos professores e também nas aulas planificadas por estes, e aquilo que efetivamente é realizado em sala de aula, moldado pela influência de inúmeros agentes e forças, entre os quais os professores, mas também os alunos e, principalmente, as suas indisciplinas.

Pode-se inferir, com base nisso e na análise realizada por Ennis (1996) sobre os impactos produzidos pela indisciplina no gerenciamento da sala de aula e nas decisões sobre os conteúdos pretendidos, a sustentação de outras duas teses sobre currículo no Brasil, a de um território em disputa, conforme expressa por Arroyo (2011), e a de território contestado, defendida por Silva (1995). Ou seja, o currículo expressa fundamentalmente 
uma relação de poder, uma disputa por afirmação de lógicas, discursos e de sujeitos da prática pedagógica, um campo onde se produzem relações sociais e escolhas, baseadas na seleção de conhecimentos, valores e saberes.

Nesse campo de relações e escolhas, marcadamente conflitivo, os professores se empenham por motivar e ensinar, reivindicam pelo interesse de seus alunos e por autonomia para adaptar o currículo tendo em vista os contextos escolares em que atuam, Mas, tendo em vista os diversos confrontos gerados por atitudes "indisciplinares", evitam situações e conteúdos potencialmente provocadores como uma forma possível de capturar a atenção de seus alunos, já que desconfiam do apoio externo à sala de aula para a resolução dos conflitos ali gerados.

É um mal estar que os angustia porque se sentem impedidos de cumprir o programa, de transmitir o conteúdo pretendido - o currículo conforme estabelecido pela escola - e passam a questionar-se em seu papel enquanto professores, em sua identidade docente, diante de um sentimento sempre presente de frustração, de desconexão com seus alunos, de estar ensinando 'apenas o básico'. Percebem-se, tal como seus alunos, descolados, desapropriados do currículo.

Conclui-se, portanto, que a indisciplina em sala de aula pode atuar como uma força desestabilizadora dos tempos, espaços, rotinas, saberes e relações que se estabelecem neste contexto. Suas expressões, significados e intensidade estariam, desse modo, diretamente relacionadas ao que se oferece aos alunos enquanto experiências de aprendizagem e possibilidades de relações e também ao modo como estas lhes são oferecidas. Contudo, suas implicações para o currículo dependeriam, em grande medida, dos modos como os professores interpretam seus significados, de como se posicionam diante da possibilidade de sua resolução ou de sua negação, e também de como se sentem habilitados ou não para o seu enfrentamento. São esses os fatores que determinam como os professores interpretam a sua prática e reelaboram suas estratégias didáticas. Diante do que percebe-se a convergência entre o clima que se estabelece no contexto da sala de aula e seus efeitos na prática docente e, consequentemente, nas decorrentes expectativas e nos contextos de aprendizagem que os professores proporcionam aos seus alunos.

Aponta-se ainda, desse modo, para a necessidade de ampliar a compreensão sobre a indisciplina e as formas de resolver ou prevenir esses conflitos em sala de aula, de modo a possibilitar outro olhar, novas perspectivas e novas referências para a prática e para a relação pedagógica, baseadas em uma nova equação quanto às relações de poder entre professores e alunos, abrindo novas perspectivas para o currículo em que se pudesse, ao mesmo tempo, produzir um contexto favorável à relação, mas também ao conteúdo, ou seja, ao ensino e à aprendizagem.

\section{Notas}

1 ERIKSON, F.; SHULTZ, J. Students' experience of the curriculum. In: JACKSON, P. E. (Ed.). Handbook of research on curriculum. New York: Mcmillan, 1992, p. 468-471.

\section{Referências}

ARROYO, M. G. Currículo, território em disputa. Petrópolis: Vozes, 2011.

ARROYO, M. G. Indagações sobre currículo: educandos e educadores: seus direitos e o currículo. Brasília: Ministério da Educação, Secretaria de Educação Básica, 2007.

ARROYO, M. G. Ofício de mestre: imagens e auto-imagens. 2. ed. Petrópolis: Vozes, 2000.

ENNIS, C. D. When avoiding confrontation leads to avoiding content: Disruptive students' impact on curriculum. Journal of Curriculum and Supervision, Alexandria, USA, n. 11, p. 145-162, 1996.

GARCIA, J. A. Escritos sobre o currículo escolar. São Paulo: Iglu, 2010a.

GARCIA, J. A. Um estudo sobre rebeldia e indisciplina na escola. In: Seminário Indisciplina na Educação Contemporânea, VI, 2010, Curitiba, Anais... Curitiba: UTP, 2010b, p. 389-402.

MOREIRA, A. F. B. A crise da teoria curricular crítica. In: COSTA, M. (Org.). V. O currículo nos limiares do contemporâneo. Rio de Janeiro: DP\&A, 1998, p. 11-36.

MOREIRA, A. F. B. Apresentação. Educação em Revista, Belo Horizonte, v. 45, p. 109-117, jun. 
2007.

MOREIRA, A. F. B.; CANDAU, V. M. (Orgs.). Indagações sobre currículo: currículo, conhecimento e cultura. Brasília: Ministério da Educação, Secretaria de Educação Básica, 2007.

MOREIRA, A. F. B.; SILVA, T. T. (Orgs.). Currículo, cultura e sociedade. 12 . ed. São Paulo: Cortez, 2011.

PEDRA, J. A. Currículo, conhecimento e suas representações. 4. ed. Campinas: Papirus, 2000.

SACRISTÁN, J. G. O currículo: uma reflexão sobre a prática. 3. ed. Porto Alegre: Artmed, 2000.

SACRISTÁN, J. G. O aluno como invenção. Porto
Alegre: Artmed, 2005.

SILVA, T. T. Currículo e identidade social: territórios contestados. In: ____. (Org.). Alienígenas na sala de aula: uma introdução aos estudos culturais em educação. 7. ed. Petrópolis: Vozes, 2008.

SILVA, T. T. Documentos de identidade: uma introdução às teorias do currículo. 3. ed. Belo Horizonte: Autêntica, 2011.

SILVA, T. T. Os novos mapas culturais e o lugar do currículo na paisagem pós-moderna. In: SILVA, T. T.; MOREIRA, A. F. B. (Orgs.). Territórios contestados: o currículo e os novos mapas políticos e culturais. Petrópolis: Vozes, 1995, p. 184-202.

\section{Sobre o autor:}

Flávio Fernando de Souza: Graduado em Filosofia (USF). Estudos de Teologia, Música e Organização do Trabalho Pedagógico. MBA em Gestão de Instituições de Educação Básica. Mestrando em Educação pela Universidade Tuiuti do Paraná (UTP), bolsista CNPq, com pesquisa sobre Currículo e Indisciplina Escolar.

Recebido em: 10/2012

Aprovado em: 06/2013 